\title{
Effects of Mid-Level Ethanol Blends on Conventional Vehicle Emissions
}

\author{
Keith Knoll \\ National Renewable Energy Laboratory \\ Brian West, Shean Huff, John Thomas \\ Oak Ridge National Laboratory \\ John Orban, Cynthia Cooper \\ Battelle Memorial Institute
}

\begin{abstract}
Tests were conducted during 2008 on 16 late-model, conventional vehicles (1999 through 2007) to determine short-term effects of mid-level ethanol blends on performance and emissions. Vehicle odometer readings ranged from 10,000 to 100,000 miles, and all vehicles conformed to federal emissions requirements for their federal certification level. The LA92 drive cycle, also known as the Unified Cycle, was used for testing as it was considered to more accurately represent real-world acceleration rates and speeds than the Federal Test Procedure (FTP) used for emissions certification testing. Test fuels were splash-blends of up to 20 volume percent ethanol with federal certification gasoline. Both regulated and unregulated air-toxic emissions were measured.
\end{abstract}

For the aggregate 16-vehicle fleet, increasing ethanol content resulted in reductions in average composite emissions of both $\mathrm{NMHC}$ and $\mathrm{CO}$ and increases in average emissions of ethanol and aldehydes. Changes in average composite emissions of $\mathrm{NMOG}$ and $\mathrm{NO}_{\mathrm{X}}$ were not statistically significant. By segregating the vehicle fleet according to power-enrichment fueling strategy, a better understanding of ethanol fuel-effect on emissions was realized. Vehicles found to apply longterm fuel trim (LTFT) to power-enrichment fueling showed no statistically significant fuel effect on NMOG, $\mathrm{NMHC}, \mathrm{CO}$ or $\mathrm{NO}_{x}$. For vehicles found to not apply LTFT to power-enrichment, statistically significant reductions in $\mathrm{NMHC}$ and $\mathrm{CO}$ were observed, as was a statistically significant increase in $\mathrm{NO}_{x}$ emissions. Effects of ethanol on NMOG and NMHC emissions were found to also be influenced by power-to-weight ratio, while the effects on $\mathrm{NO}_{x}$ emissions were found to be influenced by engine displacement.

\section{INTRODUCTION}

The United States' Energy Independence and Security Act (EISA) of 2007 calls on the nation to significantly increase its use of renewable fuels to meet its transportation energy needs. ${ }^{1}$ The law establishes a new renewable fuel standard (RFS) that requires 36 billion gallons of renewable fuel to be used in the on-road vehicle fleet by 2022. Given that ethanol is the most widely used renewable fuel in the United States and production is expected to grow steadily over the next several years, ethanol-both from corn and from cellulosic feedstocks - will likely make up a significant portion of the new renewable fuel requirements. The vast majority of ethanol currently used in the United States is blended with gasoline to create E10-gasoline with up to 10 volume percent (vol. \%) ethanol. The remaining ethanol is sold in the form of E85, a gasoline blend with as much as 85 vol. \% ethanol that can be used only in flexible-fuel vehicles (FFVs). Consumption of E85 is currently limited by both the size of the flex-fuel vehicle fleet and the number of E85 fueling stations. While U.S. automakers have committed to significantly 
ramping up production of $\mathrm{FFVs}$, only about $7 \%$ of the existing U.S. fleet is replaced each year. That means a significant number of the non-FFVs in use today will remain in the vehicle fleet for many years to come.

In light of projected growth in ethanol production, as well as the new RFS, most analysts agree that the E10 market will be saturated within the next few years, possibly as soon as 2010. Although the U.S. Department of Energy (DOE) remains committed to expanding the E85 infrastructure, that market will not be able to absorb projected volumes of ethanol in the near term. Given this reality, DOE and others have begun assessing the viability of using mid-level ethanol blends (blends of gasoline with up to $20 \mathrm{vol}$. \% ethanol) in conventional vehicles as one way to potentially accommodate growing volumes of ethanol, thereby displacing petroleum and helping the country comply with EISA.

\section{BACKGROUND}

In summer 2007, DOE initiated a test program to assess the potential impacts of mid-level ethanol blends on typical vehicles (non-FFVs) and other engines that rely on gasoline. The test program focuses specifically on the effects of E15 and E20, gasoline blended with $15 \%$ and $20 \%$ ethanol, but it includes both E0 (gasoline) and E10 as baseline fuels. Through a wide range of experimental activities, DOE is working with partners to evaluate the effects of these mid-level ethanol blends on a variety of potentially affected equipment.

Before designing the test program, a literature search was conducted indicating that insufficient data existed to predict the impacts of these fuels on current U.S. vehicles and engines. ${ }^{2}$ A study conducted by EPA in 1995 evaluated near-term effects of mid-level ethanol blends (up to $40 \mathrm{vol}$. \% ethanol) on U.S. vehicle fleet emissions. ${ }^{3}$ Tests were limited to six vehicle models and included only 1990 and 1992 model years. All vehicles were equipped with fuel injection, 3-way catalysts and closed-loop fuel control. All testing was conducted using the U.S. Environmental Protection Agency's (EPA's) Federal Test Procedure (FTP) certification drive cycle. Results of the EPA study showed that for these vehicles, as ethanol content in the fuel was increased, hydrocarbons $(\mathrm{HC})$ and carbon monoxide (CO) emissions were reduced and oxides of nitrogen $\left(\mathrm{NO}_{\mathrm{x}}\right)$ emissions were increased. Given the age of the vehicles included, however, these results may not be relevant to the current U.S. vehicle fleet. Advances in engine fuel control and catalyst technology driven by progressively more stringent emission requirements (including more aggressive certification cycles such as the US06) have likely altered the effects of ethanol on vehicle tailpipe emissions. More recently, the Orbital Engine Company conducted a mid-level ethanol blends study for Environment Australia. ${ }^{4}$ Five vehicle pairs from model years 2001 and 2002 were evaluated over 50,000 miles using unleaded gasoline and E20. Orbital showed increased emissions due to catalyst deterioration over the 50,000-mile interval for most vehicles included in its study when aged with E20. As noted previously, ${ }^{2}$ however, vehicles included in the Orbital study likely had different fueling calibrations and catalyst formulations than those used in U.S. vehicles since they were intended for the Australian market. Consequently, relevance to the U.S. vehicle fleet is not clear. The Coordinating Research Council (CRC) conducted a literature review of fuel-effect studies on vehicle emissions as well, and results were published in $2008 .^{5}$ While this review provides no information on mid-level ethanol blend effects on late-model U.S. vehicles, it does provide an excellent context for comparing other fuel composition effects on vehicle emissions.

\section{APPROACH}

Vehicle testing was conducted simultaneously at three separate emissions laboratories; Oak Ridge National Laboratory (ORNL) in Oak Ridge, TN; Transportation Research Center (TRC) in East Liberty, $\mathrm{OH}$; and the Colorado Department of Public Health and Environment (CDPHE) in Aurora, CO. Testing at all sites was conducted at a nominal temperature of $75^{\circ} \mathrm{F}$. CDPHE also conducted testing at $50^{\circ} \mathrm{F}$; however, those results are not presented here.

EMISSIONS MEASUREMENT AND VEHICLE INSTRUMENTATION - All laboratories measured emissions via full-flow dilution per Code of Federal Regulations (CFR) 40 part 86 guidelines. Concentrations of $\mathrm{CO}, \mathrm{NO}_{\mathrm{X}}$, total hydrocarbons $(\mathrm{THC})$, methane $\left(\mathrm{CH}_{4}\right)$, and carbon dioxide $\left(\mathrm{CO}_{2}\right)$ were measured by conventional analyzers. Corrections were applied to flame ionization detector (FID) measurements of hydrocarbons due to the presence of ethanol and aldehydes, per California's Non-Methane Organic Gas Test Procedure. ${ }^{6}$ All available data from each vehicle's Engine Control Unit (ECU), such as long- and short-term fuel trim values, engine and vehicle speed, and intake manifold pressure, were collected at CDPHE and ORNL via the Assembly Line Diagnostic Link (ALDL). Fuel trim data were also acquired during a two-minute idle period following each LA92 drive cycle execution as a quick check on fuel adaptation. Additional details regarding emissions analyzers and chassis dynamometer equipment used at each test lab are contained in the National Renewable Energy Laboratory (NREL)/ORNL report. $^{7}$

All labs sampled aldehydes (including formaldehyde and acetaldehyde) using dilution tunnel sample taps with gas drawn through dinitrophenylhydrazine- (DNPH)-treated silica gel cartridges at a rate of approximately $1 \mathrm{~L} / \mathrm{min}^{8}$ DNPH cartridges were then post-processed by eluting with acetonitrile and analyzing by high-performance liquid chromatography. These oxygenated compounds are reactive in the atmosphere and must be included 
when calculating nonmethane organic gas (NMOG) emissions.

Exhaust gas ethanol concentration was measured by all laboratories using the Innova Photoacoustic Multi-gas Analyzer supplied by California Analytical Instruments. This method, developed and documented by Loo and Parker $^{9}$ and now accepted by EPA, was used to batch sample individual phase emissions for ethanol concentration. Because this method includes the coupled effects of other gas species on ethanol measurement, the instrument must be calibrated and configured to measure these interfering species. Consequently, appropriate optical filters must be installed and calibrated to measure interference gases such as water vapor, ammonia, and $\mathrm{CO}_{2}$, and gas sampling and interference corrections must be enabled in the instrument during operation.

Unfortunately, for the data acquired at TRC using two new instruments, those interference measurements were not properly included, so there were errors in measurement of ethanol in the exhaust. At ORNL, ethanol measurements were near the detection limit of the Innova setup. This problem was exacerbated by the apparent "hang up" of ethanol in the sample lines - a common problem for gas phase ethanol sampling. Consequently, estimates of ethanol gas concentrations for the six vehicles tested at TRC and the four vehicles tested at ORNL were based on volume percent ethanol in the gasoline and measured THC emissions. This estimation method was developed using exhaust ethanol data acquired from the NREL/CDPHE dataset at both $50^{\circ}$ and $75^{\circ} \mathrm{F}$. This dataset included 24 points-three vehicles, four fuels, and two temperatures. These data showed strong correlation with a coefficient of determination, $\mathrm{R}^{2}$, of greater than $95 \%$. While not as desirable as direct ethanol measurement, this method was believed to provide the best estimate of ethanol concentration in the exhaust for the purposes of NMOG calculation.

A wide-range universal exhaust gas oxygen sensor (UEGO) was used on each vehicle to record the realtime fuel:air equivalence ratio. This information was necessary to understand how each test vehicle's fuel control system responded to the oxygenated fuels.

\section{EXHAUST AND CATALYST TEMPERATURE} MEASUREMENTS - Each vehicle's exhaust system was modified to allow measurement of exhaust gas temperature, catalyst core temperature and exhaust fuel:air ratio. Several key exhaust temperatures were measured on each vehicle at the following locations.

- Engine-out or pre-catalyst, measured using a 1/8 in. thermocouple located upstream of the catalyst core or in the exhaust manifold.
- Catalyst core, measured using a $1 / 16$ in. or $1 / 8$ in. thermocouple installed directly into the center of the catalyst core at $1 \mathrm{in}$. from the leading face.

- Between first and second catalysts (for vehicles with dual catalyst configuration), measured using a $1 / 8$ in. thermocouple located between catalysts.

- Second catalyst core (for vehicles with dual catalyst configuration), measured using a $1 / 16$ in. or $1 / 8$ in. thermocouple installed directly into the center of the second catalyst core at $1 \mathrm{in}$. from the leading face.

- Catalyst outlet, measured using a $1 / 8$ in. thermocouple located 6 in. downstream of the catalyst outlet.

Each vehicle's exhaust system was removed so that thermocouples, UEGO ports, and exhaust sample ports could be installed. Figure 1 shows an example exhaust system modified for this program from a 4-cylinder Toyota Camry. Only the exhaust manifold and first catalyst are shown. Similar temperature and sample ports were installed in the second catalyst and outlet pipe.

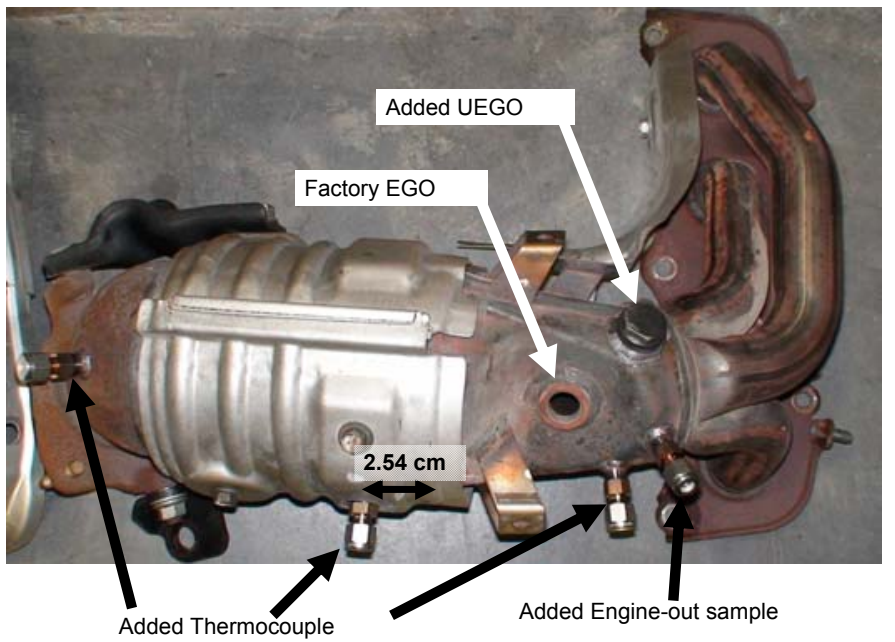

Figure 1: Typical Instrumentation of Vehicle Exhaust System

VEHICLE SELECTION - A database of U.S. registered vehicles was purchased from R. L. Polk \& Co. to characterize the population of light-duty vehicles in the U.S. fleet in 2007.

Table 1 shows the number of gasoline-powered (nonFFV) registered vehicles by model year period, manufacturer, and number of cylinders. Vehicles were selected from this database based primarily on sales volume, but also considering the vehicle manufacturer and engine configuration (number of cylinders and displacement).

Model year periods were generally defined to correspond to different regulatory periods. For the purposes of this study, vehicles were categorized by model year into four basic emission level groups. 
- Tier 0, Pre-1996: Tier 0 gaseous emissions standards were in force from 1981 through 1993 (although not denoted Tier 0 until 1987). These standards were phased out from 1994 through 1996.

- Tier 1, 1996 through 1999: Tier 1 emissions standards were phased in from 1994 through 1996 with full compliance required in 1996.

- $\quad$ Tier 2 Transitional, 2000 through 2004: The National Low Emission Vehicle program began transition to Tier 2 emissions levels from 2000 through 2004.

- $\quad$ Tier 2, 2004 through 2007: Tier 2 emissions standards were phased in for light-duty passenger vehicles beginning in 2004, with full compliance required in 2007.

Table 1: Number of Registered Gasoline-Powered Vehicles in the United States, January 2007 (thousands)

\begin{tabular}{|c|c|c|c|c|c|c|}
\hline \multirow{2}{*}{$\begin{array}{l}\text { Model } \\
\text { Year }\end{array}$} & \multirow{2}{*}{ Mfr } & \multicolumn{4}{|c|}{ Number of Cylinders } & \multirow{2}{*}{ Total } \\
\hline & & 4 & 6 & 8 & Other & \\
\hline $\begin{array}{c}\text { Pre-1996 } \\
\text { (Tier } 0 \text { I } \\
\text { older) }\end{array}$ & All & 25,948 & 34,597 & 16,512 & 1,573 & 78,630 \\
\hline \multirow{9}{*}{$\begin{array}{r}1996- \\
1999\end{array}$} & Chrysler & 1,338 & 3,943 & 1,584 & 45 & 6,910 \\
\hline & Ford & 1,894 & 5,100 & 4,021 & 100 & 11,116 \\
\hline & GM & 3,421 & 7,090 & 3,851 & 44 & 14,406 \\
\hline & Honda & 2,581 & 540 & - & 35 & 3,157 \\
\hline & Nissan & 1,146 & 914 & 28 & 0 & 2,088 \\
\hline & Toyota & 2,492 & 1,438 & 130 & 1 & 4,061 \\
\hline & VW & 542 & 188 & 6 & 0 & 737 \\
\hline & Other & 2,228 & 1,206 & 294 & 278 & 4,006 \\
\hline & Subtotal & 15,642 & 20,420 & 9,915 & 504 & 46,481 \\
\hline \multirow{5}{*}{$\begin{array}{r}2000- \\
2004\end{array}$} & Chrysler & 1,788 & 4,191 & 2,445 & 25 & 8,449 \\
\hline & Ford & 1,586 & 5,603 & 5,300 & 256 & 12,744 \\
\hline & GM & 3,474 & 9,894 & 5,996 & 88 & 19,452 \\
\hline & Honda & 3,671 & 2,154 & - & 0 & 5,825 \\
\hline & Nissan & 1,293 & 2,045 & 163 & 0 & 3,501 \\
\hline \multirow{4}{*}{$\begin{array}{c}\text { (Tier } 2 \\
\text { Trans) }\end{array}$} & Toyota & 3,778 & 3,174 & 1,001 & - & 7,953 \\
\hline & VW & 1,309 & 474 & 55 & 0 & 1,838 \\
\hline & Other & 4,466 & 4,139 & 784 & 447 & 9,836 \\
\hline & Subtotal: & 21,366 & 31,673 & 15,743 & 816 & 69,598 \\
\hline \multirow{9}{*}{$\begin{array}{c}2005- \\
2007 \\
\text { (Tier 2) }\end{array}$} & Chrysler & 767 & 2,528 & 1,071 & 8 & 4,373 \\
\hline & Ford & 715 & 2,095 & 1,934 & 43 & 4,786 \\
\hline & GM & 1,652 & 3,589 & 2,265 & 273 & 7,779 \\
\hline & Honda & 1,752 & 1,273 & - & - & 3,025 \\
\hline & Nissan & 872 & 1,088 & 238 & - & 2,199 \\
\hline & Toyota & 2,457 & 1,935 & 499 & - & 4,892 \\
\hline & VW & 288 & 91 & 41 & 181 & 601 \\
\hline & Other & 1,956 & 2,000 & 425 & 278 & 4,659 \\
\hline & Subtotal: & 10,458 & 14,599 & 6,474 & 782 & 32,313 \\
\hline \multicolumn{2}{|c|}{ Grand Total: } & 73,414 & 101,289 & 48,645 & 3,675 & 227,022 \\
\hline
\end{tabular}

Vehicles were selected to meet several analysis objectives. Of the initial 11 vehicles, three pairs were selected to represent a range of engine sizes and manufacturers, with each pair consisting of a 2003 and a 2007 vehicle from the same manufacturer and similar engine configuration. The vehicle pairs were chosen to evaluate the effect of ethanol during the progression in emissions control technology from transitional Tier 2 to full Tier 2 compliance.

- 2003 and 2007 Toyota Camry 2.4L 14

- 2003 and 2007 GM LeSabre/Lucerne 3.8L V6

- 2003 and 2007 Ford F150 5.4L V8
Five additional vehicles were selected based on sales volume data; however, some consideration was also given to vehicles that complemented those selected for EPA's EPAct (Energy Policy Act) study, which involved a similar test protocol.

- 2003 Ford Taurus 3.0L V6

- 2003 Nissan Altima 3.5L V6

- 2007 Honda Accord 2.4L 14

- 2007 Chrysler Town \& Country 3.3L V6

- 2007 GM Silverado 4.8L V8

Following this initial selection of 11 vehicles, a second set of vehicles was selected using information from auto manufacturers concerning specific models that were most likely to be sensitive to increased ethanol content in gasoline, ${ }^{11}$ while also considering sales volumes.

- 1999 Honda Civic

- 2004 VW Golf GTI

- 1999 Ford Crown Victoria

- 1999 Toyota Corolla

- 2001 Chrysler PT Cruiser

A summary of all vehicles selected for testing is included in Table 2. This table contains information about each vehicle, including odometer reading at start of test, engine family, and applicable emissions standard.

Table 2: Test Vehicle List

\begin{tabular}{|c|c|c|c|c|c|c|}
\hline OEM & Model & MY & Eng. & $\begin{array}{l}\text { Init. } \\
\text { Odo. }\end{array}$ & $\begin{array}{l}\text { EPA Engine } \\
\text { Family }\end{array}$ & $\begin{array}{l}\text { Emiss'n } \\
\text { Standard }\end{array}$ \\
\hline Honda & Accord & 2007 & $2.4 \mathrm{~L} 14$ & 11,400 & 7HNXV02.4KKC & $\begin{array}{l}\text { Tier 2, } \\
\text { Bin } 5\end{array}$ \\
\hline Nissan & Altima & 2003 & $\begin{array}{l}3.5 \mathrm{~L} \\
\text { V6 }\end{array}$ & 53,300 & $3 \mathrm{NSXV03.5C7A}$ & LEV \\
\hline Toyota & Camry & 2003 & $2.4 \mathrm{~L} \mathrm{I4}$ & 72,800 & 3TYXV02.4HHA & ULEV \\
\hline Toyota & Camry & 2007 & $2.4 \mathrm{~L} 14$ & 26,440 & 7TYXV02.4BEB & $\begin{array}{c}\text { Tier } 2 \\
\text { Bin } 5\end{array}$ \\
\hline Honda & Civic & 1999 & $1.6 \mathrm{~L} \mathrm{I} 4$ & 79,680 & XHNXV01.6TA3 & Tier 1 \\
\hline Toyota & Corolla & 1999 & $1.8 \mathrm{~L} \mathrm{I} 4$ & 96,400 & XTYXV01.8XBA & Tier 1 \\
\hline Ford & $\begin{array}{l}\text { Crown } \\
\text { Victoria }\end{array}$ & 1999 & $\begin{array}{c}4.6 \mathrm{~L} \\
\mathrm{~V} 8\end{array}$ & 50,900 & XFMXV04.6VBE & ULEV \\
\hline Ford & F150 & 2003 & $\begin{array}{r}5.4 \mathrm{~L} \\
\mathrm{~V} 8\end{array}$ & 57,000 & 3MFXT05.4PFB & Tier 1 LEV \\
\hline Ford & F150 & 2007 & $\begin{array}{r}5.4 \mathrm{~L} \\
\mathrm{~V} 8\end{array}$ & 28,600 & 7FMXT05.44H7 & $\begin{array}{l}\text { Tier } 2 \\
\text { Bin } 8\end{array}$ \\
\hline VW & Golf GTI & 2004 & $\begin{array}{r}1.8 \mathrm{~L} \\
14-\mathrm{T}\end{array}$ & 32,900 & 4ADXV01.8356 & $\begin{array}{c}\text { Tier } 2 \\
\text { Bin } 8\end{array}$ \\
\hline $\begin{array}{c}\text { GM } \\
\text { (Buick) }\end{array}$ & LeSabre & 2003 & $\begin{array}{l}3.8 \mathrm{~L} \\
\text { V6 }\end{array}$ & 78,000 & 3GMXV03.8044 & $\begin{array}{l}\text { Tier } 2 \\
\text { Bin } 8\end{array}$ \\
\hline $\begin{array}{c}\mathrm{GM} \\
\text { (Buick) }\end{array}$ & Lucerne & 2007 & $\begin{array}{r}3.8 \mathrm{~L} \\
\mathrm{~V} 6\end{array}$ & 10,000 & 7GMXV03.9146 & $\begin{array}{l}\text { Tier } 2 \\
\text { Bin } 5\end{array}$ \\
\hline Chrysler & $\begin{array}{c}\text { PT } \\
\text { Cruiser }\end{array}$ & 2001 & $2.4 \mathrm{~L} 14$ & 93,400 & 1CRXV02.4VD0 & NLEV \\
\hline GM & Silverado & 2007 & $\begin{array}{r}4.8 \mathrm{~L} \\
\text { V8 }\end{array}$ & 12,800 & 7GMXT05.3379 & $\begin{array}{c}\text { Tier } 2 \\
\text { Bin } 8\end{array}$ \\
\hline Ford & Taurus & 2003 & $\begin{array}{r}3.0 \mathrm{~L} \\
\text { V6 }\end{array}$ & 89,600 & 3FMXV03.0VF3 & $\begin{array}{l}\text { Tier } 2 \\
\text { Bin } 8\end{array}$ \\
\hline Chrysler & $\begin{array}{r}\text { Town \& } \\
\text { Cntry }\end{array}$ & 2007 & $\begin{array}{r}3.3 \mathrm{~L} \\
\text { V6 }\end{array}$ & 35,000 & 7CRXT03.8NEO & $\begin{array}{l}\text { Tier } 2 \\
\text { Bin } 5\end{array}$ \\
\hline
\end{tabular}

Although the 16 vehicles included were not selected "at random," with the exception of the three 1999 modelyear vehicles they are generally representative of the population of late-model gasoline-powered vehicles 
(model year 2000 to 2007) that were on the road in early 2007. In particular, the number of vehicles tested was nearly proportional to the population counts for each manufacturer, engine size category (number of cylinders), and emissions standard period (Transitional Tier 2: 2000 through 2004 or Tier 2: 2005 through 2007).

TEST FUELS - Four fuels of varying ethanol blend level were included in this program. Ethanol blend concentration levels were specified on a volume-percent basis and included $0 \%, 10 \%, 15 \%$, and $20 \%$ (E0, E10, $E 15$, and E20). E0 and E10 were both included as they represent legal fuels for sale in the United States. E15 and E20 represent mid-level blends which may be considered for legal sale.

The E0 test fuel was certification gasoline (Indolene) supplied by Gage Products Company. Other fuels were splash blends of this E0 fuel with the appropriate quantity of fuel-grade ethanol (per ASTM D4806). All fuel blending was done by Gage Products, and finished test fuels were delivered to each of the test labs. Splash blends were used for expediency in this pilot study because of the long iterative development process required to obtain match-blended fuels. The main differences in fuel chemistry between splash-blended and match-blended fuels are expected to be vapor pressure and hydrocarbon profile, neither of which is expected to have a significant effect on the major findings of this study. Other ongoing testing within the DOE Mid-Level Blends Test Program will validate this assertion via testing with match-blended fuels.

Table 3: Test Fuel Properties

\begin{tabular}{|c|c|c|c|c|c|c|c|c|}
\hline $\begin{array}{l}\text { Test } \\
\text { Lab }\end{array}$ & Fuel & \begin{tabular}{|c|c|} 
EtOH \\
(vol-\%)
\end{tabular} & $\begin{array}{l}\text { DVPE } \\
\text { (kPa) }\end{array}$ & \begin{tabular}{|c|c|} 
LHV \\
(MJ/kg)
\end{tabular} & SG & $\begin{array}{c}\mathbf{C} \\
\text { (wt-\%) }\end{array}$ & $\begin{array}{c}\mathbf{H} \\
(w t-\%)\end{array}$ & $\begin{array}{c}0 \\
0 \\
(w t-\%)\end{array}$ \\
\hline \multicolumn{2}{|c|}{ ASTM Method: } & D5599 & D5191 & D240 & D4052 & D5291 & D5291 & D5599 \\
\hline \multirow{4}{*}{$\begin{array}{l}\text { NREL / } \\
\text { CDPHE }\end{array}$} & E0 & 0.0 & 61.8 & 43.11 & 0.746 & 86.15 & 13.05 & 0.00 \\
\hline & E10 & 9.9 & 67.6 & 41.57 & 0.750 & 81.84 & 12.37 & 3.65 \\
\hline & E15 & 13.9 & 66.4 & 40.64 & 0.752 & 80.72 & 12.68 & 5.11 \\
\hline & E20 & 18.6 & 66.5 & 39.75 & 0.754 & 78.77 & 12.92 & 6.79 \\
\hline \multirow{4}{*}{$\begin{array}{l}\text { ORNL I } \\
\text { TRC }\end{array}$} & E0 & 0.0 & 57.9 & 43.11 & 0.746 & 86.83 & 12.97 & 0.00 \\
\hline & E10 & 9.1 & 65.4 & 41.51 & 0.750 & 82.56 & 12.62 & 3.36 \\
\hline & E15 & 14.4 & 64.3 & 40.67 & 0.752 & 80.16 & 12.52 & 5.27 \\
\hline & E20 & 19.8 & 63.6 & 39.64 & 0.755 & 79.66 & 12.84 & 7.23 \\
\hline \multirow{4}{*}{$\begin{array}{l}\text { ANL I } \\
\text { TRC }\end{array}$} & E0 & 0.0 & 58.5 & 43.13 & 0.746 & 86.83 & 12.85 & 0.00 \\
\hline & E10 & 9.9 & 64.4 & 41.39 & 0.751 & 82.29 & 12.85 & 3.62 \\
\hline & E15 & 14.3 & 64.7 & 40.50 & 0.752 & 80.58 & 13.41 & 5.24 \\
\hline & E20 & 19.6 & 63.1 & 39.64 & 0.755 & 78.97 & 12.71 & 7.17 \\
\hline
\end{tabular}

Fuels were analyzed by the Fuel Analysis Laboratory at Southwest Research Institute. Table 3 provides a partial list and summary results of analyses performed. Fuels are labeled according to test lab and nominal ethanol concentration. The three pickup trucks tested at TRC were tested under subcontract with Argonne National
Laboratory (ANL), while the three passenger cars at TRC were tested under subcontract with ORNL and used the same fuel as the vehicles tested at ORNL. Figure 2 provides distillation properties of the fuels used based on an analysis of the NREL fuel set, including tabulated values for $T_{10}, T_{50}$, and $T_{90}$ for each ethanol concentration.

Although test fuels were expected to be from common blend stocks, some differences in fuel properties were observed. Fuels were specified to be within $1 \%$ of nominal ethanol content. Fuels at the NREL test lab were found to be slightly below this specification at 13.9 vol. \% ethanol for the E15 fuel and 18.6 vol. \% ethanol for the E20 fuel. Variations in dry vapor pressure equivalent (DVPE) consistent with these ethanol variations were observed. While these differences were not expected to significantly impact emissions or catalyst temperature trends, they should be kept in mind when considering the results.

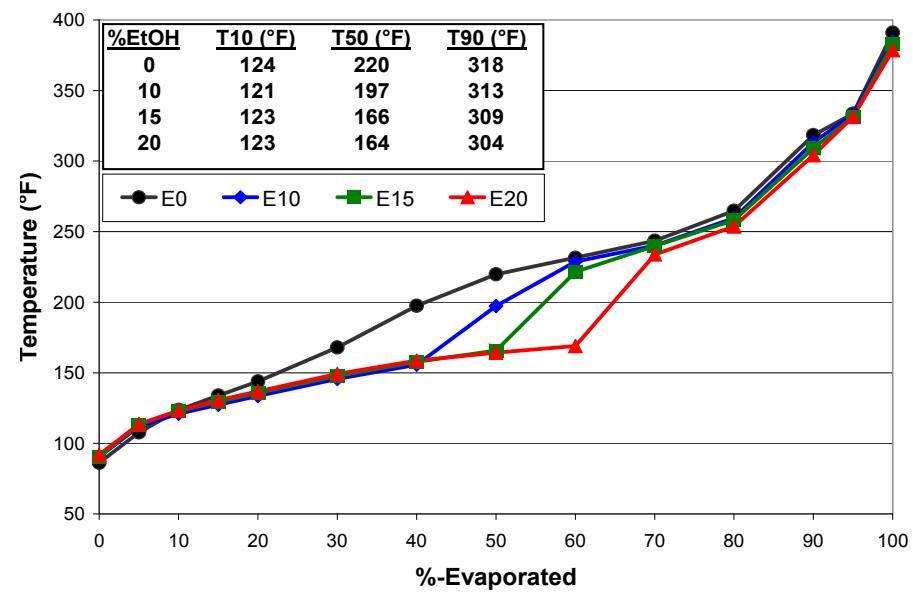

Figure 2: Distillation curves for NREL fuel set

TEST CYCLE - Emissions were determined using the LA92 drive cycle, also known as the Unified Cycle. ${ }^{12}$ The LA92 was chosen based on consultation with staff at EPA, the fact that EPA is using the LA92 in the EPAct program, ${ }^{10}$ and the consensus that it is the single drive cycle most representative of real-world driving in the United States. The LA92 was executed as a three-phase test, similar to the FTP cycle, incorporating a 10-minute engine-off hot-soak period following phase 2. Phase 3 was then run as a hot-start replicate of the cold-start phase 1. Composite emissions were calculated using the same weighting factors as specified for the FTP, per CFR requirements.

Power-enrichment fuel trim strategy for each vehicle was determined using a modification of the wide-open throttle (WOT) acceleration sulfur purge cycle used in the CRC E-60 test program. ${ }^{13}$ An explanation of powerenrichment fuel trim strategies, why they were determined experimentally, and why they are important is provided below. The modified cycle used is shown in Figure 3. This WOT cycle included a five-minute steady- 
state temperature stabilization period followed by five consecutive standing start WOT accelerations from 0 to $80 \mathrm{mph}$. The entire protocol was executed twice, and the last five WOT accelerations were used for analysis. These WOT accelerations were used to force each test vehicle into a power-enrichment mode in which openloop fuel trim strategies could be investigated.

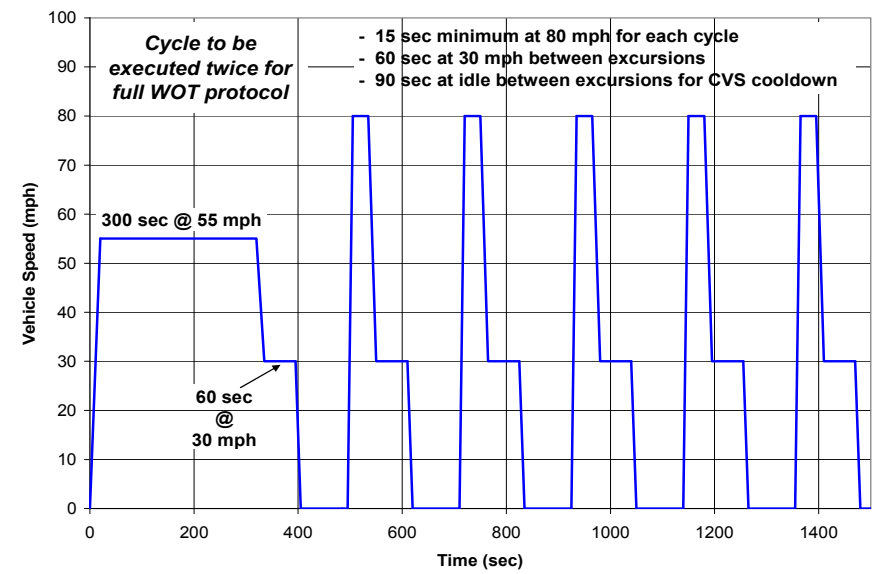

Figure 3: Modified CRC E-60 WOT drive cycle

STATISTICAL ANALYSIS - Two types of statistical analyses were performed. First, an analysis was conducted to determine whether the relative change in emissions when using ethanol in the fuel (E10, E15, or E20) versus E0, averaged across all vehicles, was different from zero. This approach involved calculating the change in average measured emissions and fuel economy (based on triplicate emissions tests) for each vehicle between the fuels containing ethanol (E10, E15, and E20) and E0. The relative change for each vehicle was obtained by dividing by the average mass emissions change with the value for E0. Then a standard t-test was performed to determine whether the average change in emissions or fuel economy was different from zero at the $95 \%$ confidence level. For this analysis, the 16 tested vehicles were treated as a random sample from the population of late model vehicles (model years 1999 to 2007 ) in the United States in early 2007 . Although the vehicles were not selected at random, they are generally representative of the target population, as discussed above.

Additional analyses were performed to determine if certain vehicle or engine characteristics were coupled with ethanol fuel effects on emissions. Characteristics studied included whether or not the engine applied LTFT to power enrichment fueling, power-to-weight ratio, and engine displacement. Power-enrichment fuel trim effects were first considered alone, followed by a fixed-effect linear regression analysis to determine coupling of these effects. Fixed effects included fuel type, the three engine characteristics (noted above), and all two- and threefactor interactions of each fuel type with one or two engine characteristics. This approach permitted testing of hypotheses concerning the overall ethanol effects (confirming results of the t-tests) as well as whether engine characteristics (or combinations of characteristics) affected the way in which ethanol changed emissions. The model accounted for random effects of replicate tests, test set-up, and random differences between vehicles. Log transformations were applied to the dependent variables, as appropriate, to achieve a normal distribution of errors. Analyses were performed on the full model (all three engine characteristics) as well as various reduced models after excluding factors that were not statistically significant.

VEHICLE PREPARATION AND FUEL ADAPTATION Before the start of testing, each vehicle was inspected to ensure that all emission control hardware was intact, and an ECU scan was conducted to confirm no on-board diagnostic (OBDII) faults were present. Each vehicle then underwent an initial crankcase oil, oil filter, and air filter replacement. Engine oil and filters were per the manufacturer's recommendations. Each vehicle was then driven through three US06 drive cycles to stabilize the engine oil by eliminating the higher volatility components that may have an effect on vehicle emissions. Each vehicle's ECU was again scanned before initiation of testing to confirm that there were no existing or pending OBDIl faults.

Following initial preparation, vehicles at CDPHE and ORNL were tested on the Federal Test Procedure (FTP) and Highway Fuel Economy Test protocols to determine city and highway fuel economy for comparison to published EPA data. Provided these evaluations yielded fuel economy results within $10 \%$ of EPA database values, dynamometer setup and vehicle operation were considered to be acceptable.

Following acquisition and preparation, each vehicle was fueled with the appropriate test fuel and adapted according to the fuel change protocol described below. This fuel change protocol was performed for every fuel change throughout the test program.

1. Drain fuel tank using in-tank fuel pump

2. Key on for 30 seconds, confirm gauge reading and allow vehicle to register new fueling event

3. Add half tank of new test fuel

4. Drive 550 (5 minutes at $50 \mathrm{mph}$ ), then double US06 test protocol

5. Drain tank using in-tank fuel pump

6. Key on for 30 seconds, confirm gauge reading and allow vehicle to register new fueling event

7. Add half tank of new test fuel

8. Proceed to emissions test preparation

The following protocol was executed following fuel adaptation and prior to the first emissions test run on each fuel. The second and third emissions tests followed consecutively without a repeat of the entire preparation cycle. 
1. Vehicle precondition: Drive 550 cycle followed by complete LA4 test cycle followed by LA92 test cycle. Idle vehicle in Park for 2 minutes following completion of LA92, then key off.

Note: Vehicle precondition was performed following overnight vehicle soak at intended test temperature.

2. Soak vehicle overnight at intended test temperature

3. Execute LA92 emissions test protocol

4. Idle vehicle in Park for 2 minutes following each test, then key off

5. Push vehicle (with key in off position) from chassis dynamometer to parking/staging area

6. Perform subsequent vehicle tests at the same test temperature with only an LA92 precondition. (Previous vehicle test may be used to satisfy precondition requirement provided test temperature is equivalent.)

7. Check for existing or pending OBDII fault codes following each LA92 test and record result in vehicle log book

At the conclusion of all emissions tests on a given fuel, WOT test protocols were conducted as described above.

The following fuel testing sequence was followed for all vehicles.
1. E0 baseline
2. E20
3. E10
4. E15
5. E0 repeat

Initial E0 testing was conducted to obtain a performance baseline before the introduction of ethanol blended fuels. E20 fuel was tested immediately following E0 to precipitate any possible malfunction indicator light (MIL) occurrences due to fuel trim effects or clogged filters resulting from the increased solvency of E20 fuel. Repetition of EO fueling at the conclusion of emissions testing was done to test for any drift in the E0 data over time and to see whether the short-term exposure to intermediate ethanol blends or the WOT testing might have caused any notable change to the emissions control system function.

\section{RESULTS AND DISCUSSION}

EMISSIONS DRIFT ANALYSIS - Emissions drift over the duration of the test program was evaluated by comparing emissions from the baseline EO runs with results from the repeat EO runs conducted at the conclusion of testing. Drift analysis was intended to identify any significant changes in vehicle emissions and/or measurement system stability over the course of testing as well as provide context for the fuel-effect emission trends being analyzed in this study. Emissions drift might have occurred as a result of vehicle operation using mid-level ethanol blends over numerous drive cycles, including LA92, FTP, US06 and the WOT cycle described above. Drift in average mass emissions for each vehicle was first calculated by comparing averages of at least three replicate tests from each test series; E0 baseline and EO repeat. Percent changes in mass emissions were then calculated and averaged across the vehicle fleet. The standard t-test was used, as described above, to determine statistically significant trends in the observed result.

Figure 4 shows emissions drift from beginning to end of test; error bars indicate 95\% confidence intervals. Although typical scatter in the data was observed, there was no statistically significant drift in NMOG, NMHC, or $\mathrm{CO}$ emissions. $\mathrm{NO}_{x}$ emissions showed a statistically significant reduction of about $18 \%$, and $\mathrm{CO}_{2}$ showed a reduction of about $2 \%$. No particular vehicle subset defined by model year, vehicle miles, or powerenrichment fueling strategy (explained below) appeared to have biased these results.

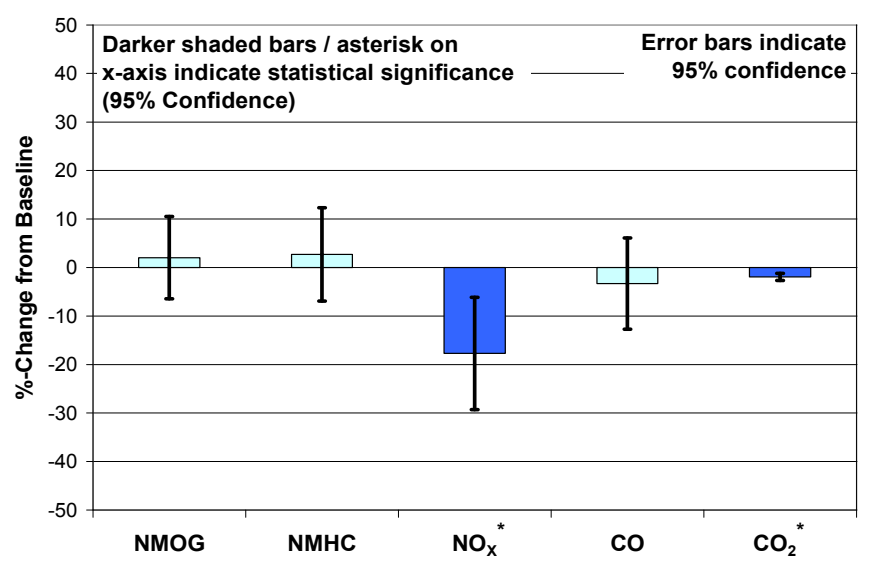

Figure 4: Emissions drift from initial baseline to final repeat using E0 fuel

Reasons for the observed $\mathrm{NO}_{\mathrm{x}}$ drift are not known; however, one possible explanation may be the repetitive sulfur purge cycles used throughout this test program. Three-way catalysts typically contain base metal promoters such as barium; ${ }^{14,15}$ these materials are known to store $\mathrm{NO}_{\mathrm{x}}{ }^{16}$ These materials also have a high affinity for sulfur, and sulfur has been shown to limit catalyst effectiveness; the largest effect is on $\mathrm{NO}_{x}$ performance. ${ }^{16,17,18,19}$ Catalyst function has been shown to recover when sulfur is purged through hot, rich operation such as that reached during the repeated WOT cycles used in the current study. ${ }^{17,18,19}$ It may be that the vehicles' exposure to repeated WOT cycles resulted in continual improvement of $\mathrm{NO}_{x}$ reduction.

FUEL ADAPTATION ANALYSIS - For a fuel effect study, vehicle adaptation to each test fuel is critical. The fuel adaptation procedure described above was arrived at following careful consideration of previous work in the literature as well as consultation with staff at EPA. Suitability of the adaptation protocol was validated by both analysis of the fuel trim information acquired during 
test and a review of emissions drift for each vehicle at each fuel-ethanol level.

For the NREL/CDPHE vehicle dataset, fuel trim information was acquired continuously during LA92 cycle execution and a cycle-average value was determined for each test. Analysis of this information showed good adaptation to each fuel, and fuel trim values correlated well with percent ethanol in the fuel. Figure 5 shows a typical result. For the ORNL vehicle dataset, fuel trim information was acquired during the two-minute idle period at the end of each LA92 cycle execution. Again, all vehicles showed consistent adaption to each test fuel. Considering all fuel trim data acquired, clear differentiation in both fuel trim and emissions results suggested that fuel adaptation on all vehicles was adequate to determine fuel-effect variation on emissions.

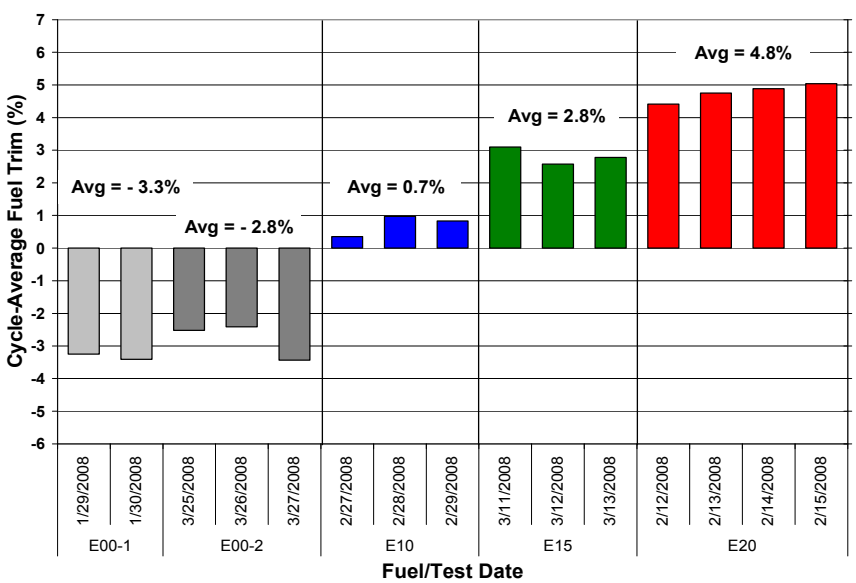

Figure 5: Fuel trim comparison based on three-phase LA92 average values

\section{COMPOSITE EMISSIONS-AGGREGATE VEHICLE} SET - Ethanol fuel effects on composite vehicle emissions were first considered in aggregate for the 16vehicle fleet. Composite emissions were calculated as a weighted average from the three-phase LA92 cycle, computed in the same way that EPA computes the FTP composite emissions for regulatory purposes. Additional analyses considering power-enrichment fueling strategy, emissions certification level, and phase emissions are discussed below. All results are presented in terms of statistical significance based on a Student's t-test. "Statistically significant" results are those that can be stated with $95 \%$ confidence or better.

Aggregate vehicle emissions trends are shown in Figures 6 and 7. Figure 6 shows percent-change in regulated tailpipe emissions and fuel economy versus E0, while Figure 7 shows the magnitude-change of ethanol and percent-change of acetaldehyde and formaldehyde emissions relative to E0. Note that ethanol mass emissions are multiplied by 10 to allow for common y-axis scaling. Individual data points represent individual vehicle results based on averages of at least three replicate tests, while bars indicate changes for all vehicles on average. Darker shaded bars indicate results found to be statistically significant, while lighter shaded bars indicate results that are not statistically significant. Statistical significance is also indicated by an asterisk on the $\mathrm{x}$-axis.

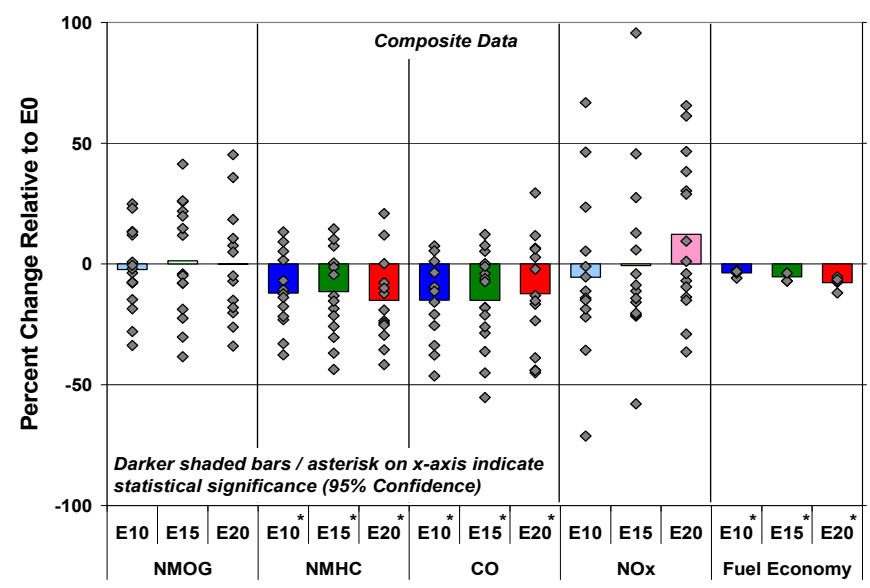

Figure 6: Average percent change in emissions and fuel economy relative to E0

While the data showed considerable scatter, some clear trends were observed. NMHC and $\mathrm{CO}$ both showed statistically significant reductions with increasing ethanol. For both pollutants, this reduction was on the order of $10 \%$ to $15 \%$ and occurred primarily with a $10 \%$ ethanol addition. Trends for E15 and E20 were similar to those for E10, suggesting minimal if any effect of ethanol blend from E10 thru E20. Fuel economy showed a statistically significant reduction with increasing ethanol content; the percent reduction tracked closely with the measured energy content of the fuel. NMOG and $\mathrm{NO}_{x}$ emissions showed no statistically significant trend. Percent change in $\mathrm{NO}_{\mathrm{x}}$ emissions showed the highest scatter of all regulated pollutants. There was no correlation between percent change in $\mathrm{NO}_{x}$ emissions and measured mass emissions rates, suggesting that low- and high-emitting vehicles were not confounding these results.

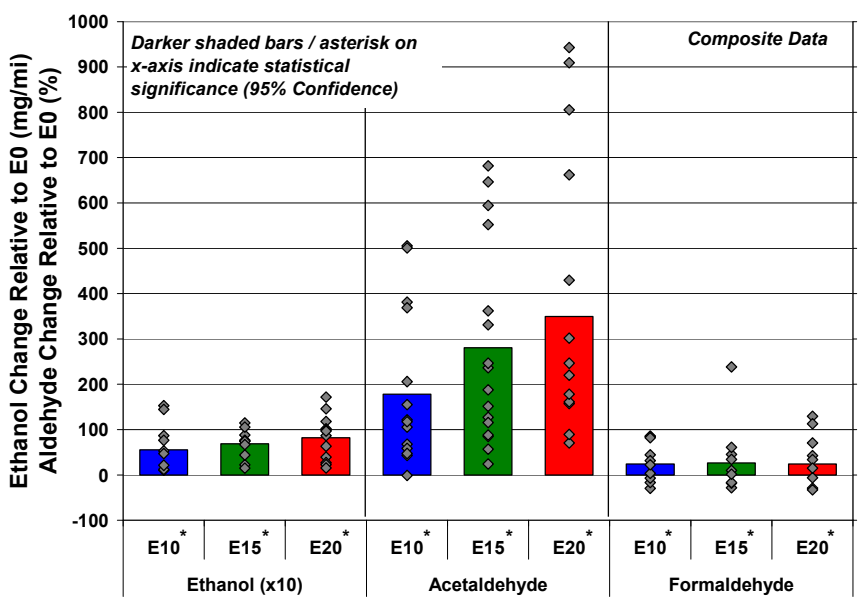

Figure 7: Average change in composite ethanol and aldehyde emissions relative to E0 
Ethanol and acetaldehyde emissions showed statistically significant increases for all ethanol fuels relative to E0. Ethanol emissions increased dramatically from EO to $\mathrm{E} 10$, and then linearly but to a much lesser degree from $\mathrm{E} 10$ to E20. Ethanol emissions for E10 were on average $5.6 \mathrm{mg} / \mathrm{mile}$ above EO values, while average increases for E15 and E20 were 6.9 and $8.2 \mathrm{mg} / \mathrm{mile}$, respectively. Acetaldehyde emission increases were nearly linear with ethanol content and were seen to increase on average by about $350 \%$ for E20 relative to E0. This effect is generally lower than expected based on historical data from the literature which would suggest an increase of about $600 \%$ based on vehicles operating on E85 (nominally $\sim 80 \%$ ethanol assumed). ${ }^{20}$ For the current study, the largest percent increases in acetaldehyde were driven entirely by the lower acetaldehyde-emitting vehicle set. All vehicles with acetaldehyde increases above $500 \%$ relative to E0 for any fuel had mass emission rates below average (less than $0.7 \mathrm{mg} / \mathrm{mile}$ ) for all fuels tested. On average, acetaldehyde mass emissions increased by $0.38,0.70$, and $0.81 \mathrm{mg} / \mathrm{mile}$ for E10, E15, and E20, respectively, relative to E0. Average acetaldehyde emissions for E0 fuel were $0.35 \mathrm{mg} / \mathrm{mile}$.

Formaldehyde emissions showed statistically significant increases for all ethanol concentrations relative to E0, but no significant change beyond $10 \%$ ethanol addition. Fleet average formaldehyde mass emissions rates were below $1.0 \mathrm{mg} / \mathrm{mile}$ for all fuels tested and below 1.5 $\mathrm{mg} / \mathrm{mile}$ for all vehicles except for the oldest, highest mileage vehicle in the study which showed formaldehyde mass emission rates between 2.5 and $3.5 \mathrm{mg} / \mathrm{mile}$ for all fuels.

POWER-ENRICHMENT FUEL TRIM STRATEGIES The exhaust gas oxygen (EGO) sensor used on most modern vehicles (post-1970s) is a switching type oxygen sensor. This type of sensor can determine whether the engine is running rich or lean of stoichiometric but does not indicate how rich or how lean. Consequently, feedback from this sensor can be used only to actively adjust for differences in the fuel:air equivalence ratio from calibrated values during closed-loop, stoichiometric operation. The engine control unit (ECU) typically stores such fuel trim information in long-term fuel trim, an array of fuel trim values covering a wide range of engine operating conditions. LTFT is used to adjust engine fueling whenever the engine operates under similar operating conditions. In contrast, short-term fuel trim (STFT) is used to account for more immediate fluctuations in engine fuel trim requirements and is assumed to be a single value applied to instantaneous operating conditions. LTFT is typically stored in an ECU's nonvolatile memory, meaning it is retained following key-off, while STFT is assumed to be stored in an ECU's volatile memory, meaning it is erased following each key-off event. Both fuel trim values are intended to compensate for variation in vehicle components, such as fuel pump pressure, injector flow rate, induction system air leaks and various sensor accuracies, both from original build and from deterioration over life. Both fuel trim values are also intended to compensate for variations in fuel composition such as oxygen (or ethanol) content.

During certain operating conditions, such as wide open throttle, the ECU switches from closed-loop stoichiometric operation to a power-enrichment (i.e., fuel-enrichment) mode to reduce exhaust gas temperatures and protect both engine and exhaust emission control components from thermal damage. This enrichment mode is typically open-loop, using a fuel enrichment strategy preprogrammed into the ECU. Two fuel trim strategies are commonly employed during power-enrichment: those that apply LTFT to powerenrichment fueling and those that do not. ${ }^{11}$ Both powerenrichment strategies have sound technical rationales; however, a strategy that does not employ LTFT during power enrichment may be more susceptible to engine and emission control system damage during high load operation because of unanticipated variation in vehicle components or fuel composition.

Polling engine manufacturers and calibrators about the fueling strategy used for power enrichment on each vehicle led to considerable uncertainty. Calibration strategies were variable among engine manufacturers, across engine models, and even across model years for a specific vehicle model. For legacy vehicles, it was often difficult to identify the version of ECU code that was installed, since multiple releases over the engine life were possible. To further complicate matters, even when an engine calibrator was certain of the power-enrichment strategy used for a particular vehicle, actual testing would not always yield consistent results. Differences may have arisen either due to the fuel adaptation protocol or the length of time allowed in each adaptation cell. Also, coding structure may have prohibited practical LTFT learning because power-enrichment was applied before adequate time was available for learning during closed-loop operation.

Power-enrichment fuel trim strategies were therefore determined experimentally in this study using the WOT protocol described previously. To verify proper interpretation of power-enrichment strategy, two of the vehicles found to not apply LTFT to power-enrichment were further tested using EPA's standard road cycle (SRC). ${ }^{21}$ The SRC is a dynamometer driving schedule developed by EPA for vehicle aging and covers a broad portion of the engine operating map. Following adaptation to E20 fuel, the two vehicles were operated over six consecutive SRC cycles and retested according to the WOT protocol. Power-enrichment fueling strategies for both vehicles remained unchanged.

Of the 16 vehicles included in the current study, 7 were determined to not apply LTFT to power-enrichment operation. For each of these vehicles, the decrease in fuel:air equivalence ratio observed during powerenrichment at WOT roughly corresponded on a percent basis with the increased oxygen content of the fuel. For 
the balance of vehicles tested (9 of 16), the fuel:air equivalence ratio determined during power-enrichment operation remained nearly constant as the ethanol content in the fuel was increased.

POWER-ENRICHMENT-DRIVE CYCLE EFFECTS The LA92 cycle was chosen for the current test program because it was generally considered to be the best single drive cycle representative of "real-world" U.S. driving behavior. Since the cycle's development in the early 1990s, driving behavior has likely become even more aggressive, suggesting that the LA92 may very well underpredict typical driving aggressiveness. ${ }^{22}$ Positive kinetic energy (PKE) is a parameter often used to indicate aggressiveness of various vehicle drive cycles. $^{23,24}$ PKE represents the positive acceleration kinetic energy per unit distance and is calculated according to the equation

$$
P K E=\frac{\sum\left(V_{\text {final }}^{2}-V_{\text {initial }}^{2}\right)_{a>0}}{\text { distance }}
$$

where

$$
\begin{aligned}
& V_{\text {final }}=\text { final velocity } \\
& V_{\text {initial }}=\text { initial velocity } \\
& a>0 \text { means for positive accelerations only } \\
& \text { distance }=\text { total distance traveled in trip or micro-trip. }
\end{aligned}
$$

A mean value of PKE can then be calculated by averaging the second-by-second values for all positive accelerations. To provide a perspective on drive cycle aggressiveness, these mean PKE values can be compared. For the LA92 cycle, a mean PKE of $0.46 \mathrm{~m} / \mathrm{s}^{2}$ is calculated, whereas for the FTP cycle, the mean PKE is $0.36 \mathrm{~m} / \mathrm{s}^{2}$. Based on this metric, the LA92 drive cycle is about $29 \%$ more aggressive than the FTP drive cycle.

In closely examining fuel:air ratio during LA92 cycle execution, it was determined that vehicles included in the current study employed some measure of fuel enrichment throughout the drive cycle after initial warmup. Fuel enrichment was considered to have occurred when measured lambda was below a threshold value of 0.95. As a comparison, five of the vehicles included in the current study were also operated on the FTP drive cycle. Comparison of continuous fuel:air ratio measurements for these five vehicles showed increased power-enrichment during LA92 operation when compared with the FTP drive cycle. Not surprisingly, the percent time at power-enrichment depended on the vehicle power-to-weight ratio; higher power-to-weight ratio resulted in less power enrichment on either cycle. For the five vehicles evaluated, LA92 cycle execution resulted in about a $25 \%$ or greater increase in power enrichment relative to FTP cycle execution. Because power enrichment is expected to heavily influence drive cycle emissions, and in consideration of the clear differentiation in power-enrichment fueling strategies within the vehicle fleet, the vehicle set was segregated according to power-enrichment fueling strategy to determine any possible influence on emissions results.

COMPOSITE EMISSIONS-POWER ENRICHMENT FUEL TRIM EFFECTS - Figures 10 and 11 show composite vehicle emission trends for the 16-vehicle fleet; average values are separated according to powerenrichment fueling strategy. Red and pink shaded bars indicate average values for those vehicles determined not to apply LTFT to adjust fuel trim during powerenrichment operation, while blue and light blue bars indicate average values for those vehicles determined to apply LTFT during power enrichment. Darker shaded bars indicate statistically significant results at the $95 \%$ confidence level. Individual data points are included to show individual vehicle results based on at least three replicate tests. Figure 10 shows regulated emissions and fuel economy as a percent change relative to E0. Figure 11 shows ethanol and aldehyde emissions change relative to E0; ethanol is shown as a magnitude change while acetaldehyde and formaldehyde are shown as a percent-change. As shown in Figure 10, vehicles found to apply LTFT to power-enrichment operation showed no statistically significant change in NMOG, NMHC, CO or $\mathrm{NO}_{x}$ emissions for any ethanol content through E20 relative to $\mathrm{E} 0$.

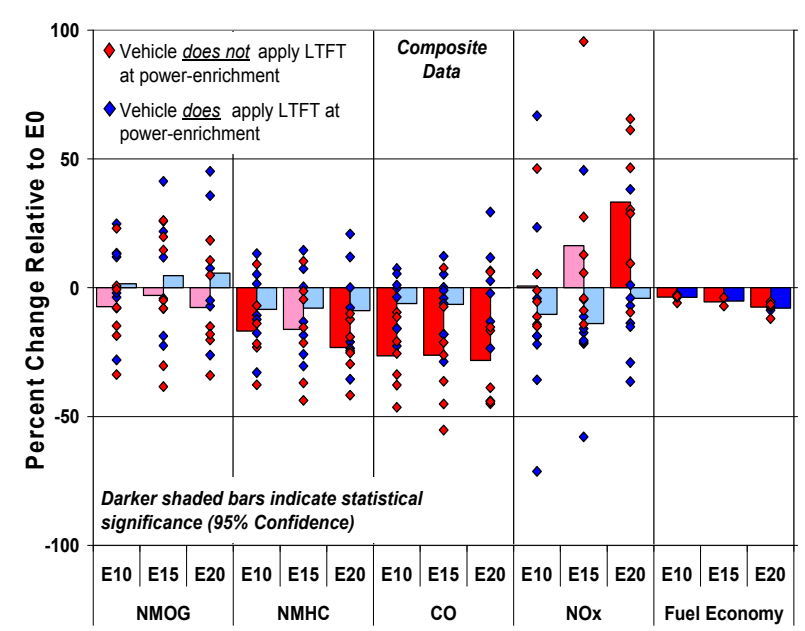

Figure 10: Percent change in composite emissions and fuel economy relative to E0

Those vehicles found not to apply LTFT to power enrichment operation showed no statistically significant change in NMOG emissions; however, statistically significant effects were observed for $\mathrm{NMHC}, \mathrm{CO}$, and $\mathrm{NO}_{x}$. NMHC and $\mathrm{CO}$ both showed statistically significant reductions on the order of $20 \%$ to $25 \%$ relative to E0 for all ethanol concentrations (with the exception of NMHC at E15, which was determined to not be statistically significant). $\mathrm{NO}_{\mathrm{x}}$ emissions for this vehicle subgroup showed a statistically significant increase of about $35 \%$ for E20 fuel relative to E0. E10 and E15 fuels showed no statistically significant $\mathrm{NO}_{x}$ effect. Average $\mathrm{NO}_{x}$ mass 
emission rates were about $0.1 \mathrm{~g} / \mathrm{mile}$ for all ethanol concentrations. Two of the five vehicles with the highest percent $\mathrm{NO}_{\mathrm{x}}$ increases for $\mathrm{E} 20$ also had $\mathrm{NO}_{\mathrm{X}}$ mass emissions at or above the average value, suggesting these results were not skewed by the lowest emitting vehicles. Although mass emissions rates were much lower for the vehicles tested here, these trends were generally consistent with earlier results found by EPA for Tier 0 vehicle effects. ${ }^{3}$

As shown in Figure 11, ethanol and acetaldehyde emissions exhibited statistically significant increases for both vehicle subgroups when compared with E0. Vehicles that did not apply LTFT to power-enrichment exhibited slightly higher ethanol increases relative to E0 than did vehicles found to apply LTFT to power enrichment. Acetaldehyde increases were roughly linearly proportional to ethanol content. Vehicles that applied LTFT to power enrichment tended to show slightly higher increases in acetaldehyde relative to E0. This differentiation in acetaldehyde emissions according to power-enrichment fueling strategy was not skewed by lower emitting vehicles. Statistically significant formaldehyde increases were observed only for vehicles that applied LTFT to power-enrichment operation and only for E10 and E20 fueling. Formaldehyde increases for the vehicle subgroup that applied LTFT to power enrichment were on the order of $35 \%$ to $45 \%$ relative to E0 and occurred primarily from E0 to E10.

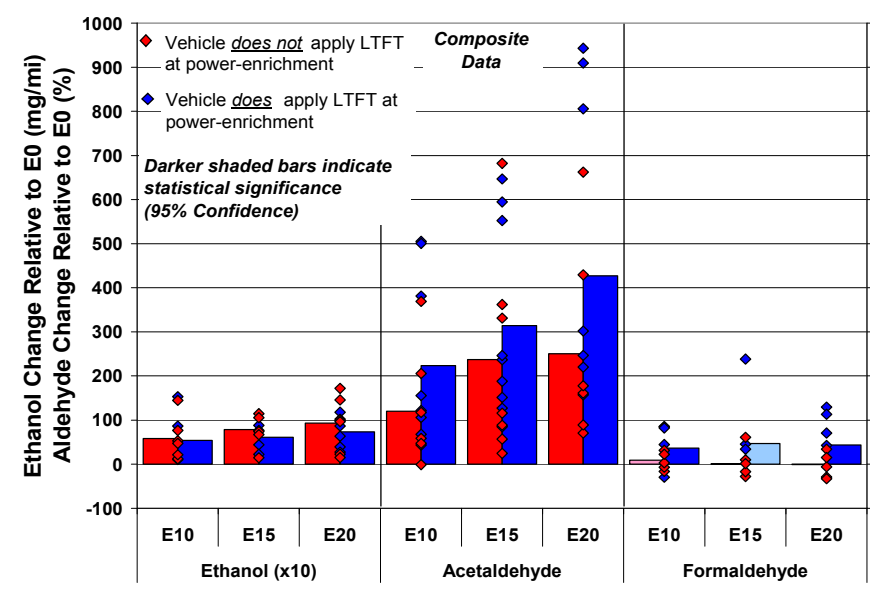

Figure 11: Average change in composite ethanol and aldehyde emissions relative to E0

COMPOSITE EMISSIONS-OTHER ENGINE CHARACTERISTIC EFFECTS - Additional analyses were performed to determine if differences in certain vehicle/engine characteristics influenced the effects of ethanol on tailpipe emissions. Three factors were included in this analysis: power-enrichment fuel trim strategy, power-to-weight ratio, and engine displacement. Power-to-weight ratio was calculated using published rated power values for each engine and equivalent test weights (ETW) for each vehicle (curb weight $+300 \mathrm{lbm}$ ); units were in $\mathrm{hp} / \mathrm{lb}$.
Fixed-effect analyses were conducted with three objectives in mind:

1. Determine effect of ethanol concentration on emissions and fuel economy

2. Determine if the effect of ethanol on emissions varied according to vehicle/engine characteristics (i.e., a significant two-way interaction between a vehicle/engine characteristic and ethanol concentration)

3. Determine if the effect of ethanol on emissions varied with different combinations of vehicle/engine characteristics (i.e., a significant three-way interaction among two vehicle/engine characteristics and ethanol concentration).

Analyses were performed using the full model (all factors included) as well as various reduced models after excluding factors that were not statistically significant. Consistency of results among different levels of ethanol (E20 versus E0, E15 versus E0, and E10 versus E0) were considered in evaluating the results.

Results from this analysis relative to the first objective were consistent with findings from the t-test method discussed in the previous section. Statistically significant results pertaining to the second and third objective are discussed below, and shown in Figures 12 through 15.

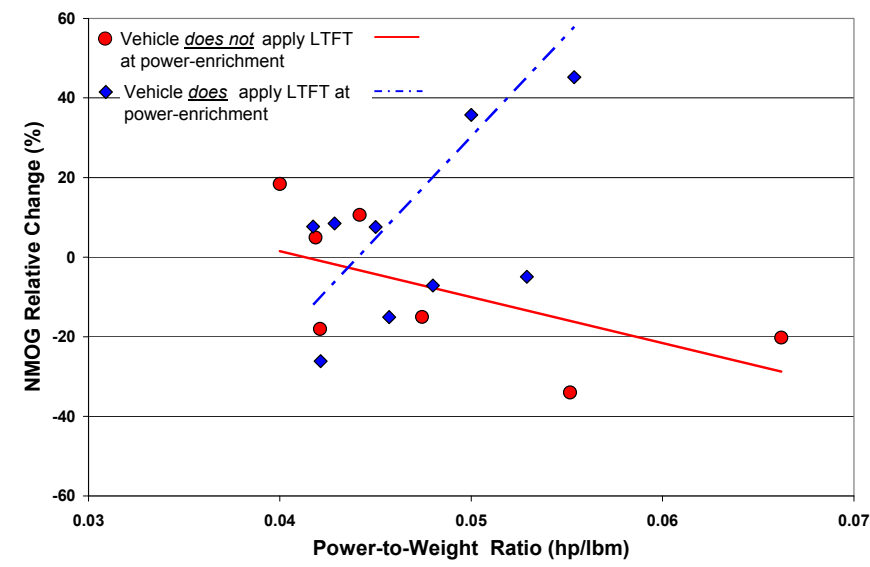

Figure 12: Change in relative NMOG composite emissions with $20 \%$ fuel ethanol by LTFT strategy and power-to-weight ratio. Interaction of LTFT and power-toweight ratio is statistically significant at the $95 \%$ confidence level.

Although there was no statistically significant difference in average emissions of NMOG when using various levels of ethanol in the fuel, as shown in Figures 6 and 10 , there was a statistically significant three-way interaction involving ethanol, power-enrichment fuel trim strategy, and power-to-weight ratio. This effect was statistically significant (at the $95 \%$ confidence level) when all three ethanol fuels (E10, E15, and E20) were compared with E0. As shown in Figure 12, the relative change in NMOG emissions (from EO to E20) was minimal for all vehicles with a power-to-weight ratio 
between 0.04 and 0.05 ; however, as the vehicle powerto-weight ratio increased, ethanol tended to produce a larger increase in NMOG emissions for vehicles found to apply LTFT during power enrichment. For vehicles found to not apply LTFT during power enrichment, a decreasing trend in NMOG was observed.

Findings for NMHC were very similar to those for NMOG, except (a) there was a statistically significant decrease in NMHC emissions averaged across all vehicles, as discussed earlier, and (b) the statistical significance of the interaction between powerenrichment fuel trim strategy and power-to-weight ratio was only marginally significant (at the $90 \%$ confidence level). Figure 13 shows the relationship between the change in $\mathrm{NMHC}$ emissions relative to EO versus powerto-weight ratio for the two vehicle subgroups.

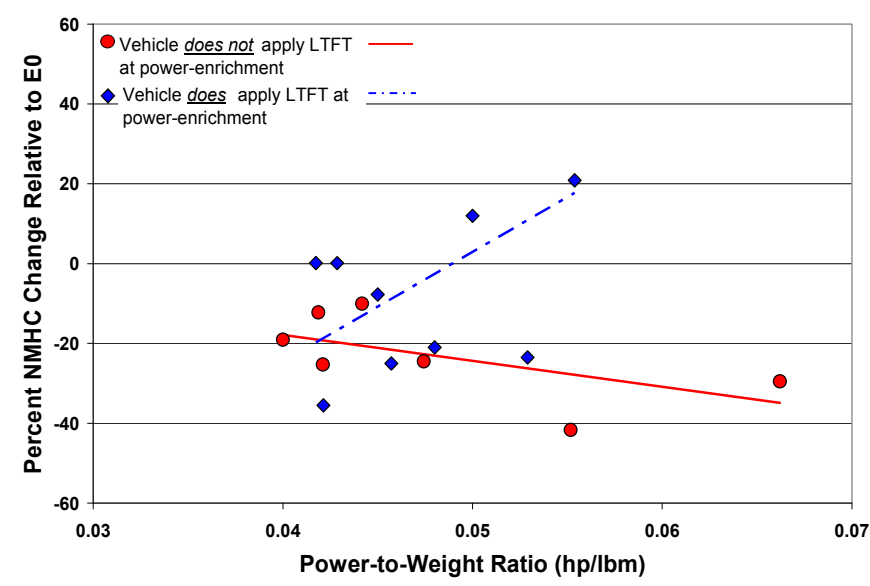

Figure 13: Change in relative NMHC composite emissions with $20 \%$ fuel ethanol by LTFT strategy and power-to-weight ratio. Interaction of LTFT strategy and power-to-weight ratio is marginally significant at the $90 \%$ confidence level.

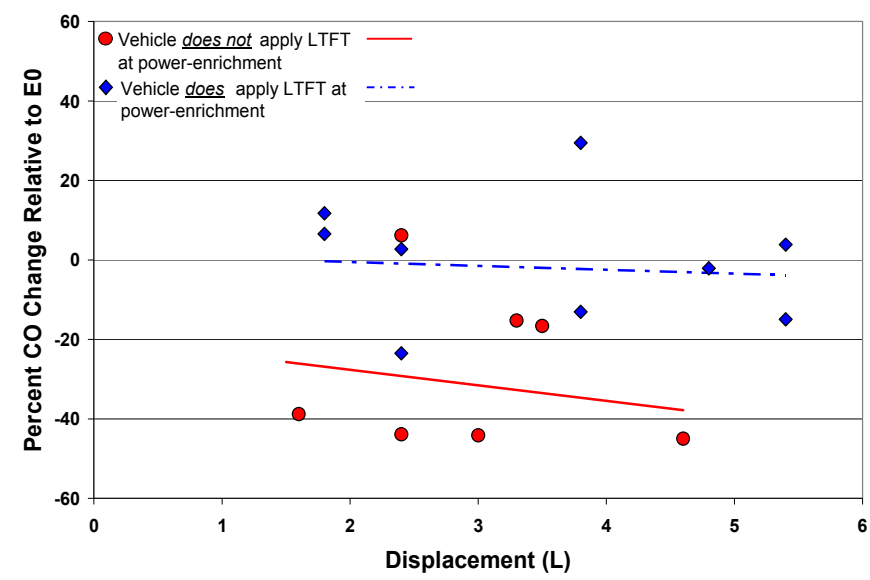

Figure 14: Change in relative $\mathrm{CO}$ composite emissions with $20 \%$ fuel ethanol by LTFT strategy and engine displacement. Effect of LTFT strategy is statistically significant at the $95 \%$ confidence level, whereas effect of engine displacement is not statistically significant.
The effect of power-enrichment fuel trim strategy on the relative change in $\mathrm{CO}$ emissions was statistically significant at the $95 \%$ confidence level for all three fuel ethanol levels as shown previously in Figure 6. As shown in Figure 10 and confirmed in Figure 14, the average effect of $20 \%$ ethanol on CO emissions was negligible for vehicles that applied LTFT at power enrichment; however, there was an average of 30 percent reduction in $\mathrm{CO}$ emissions among vehicles that did not apply LTFT at power enrichment. Effects of engine displacement and power-to-weight ratio (not shown) on the change in $\mathrm{CO}$ emissions were not statistically significant.

The effect of $20 \%$ ethanol on $\mathrm{NO}_{x}$ emissions is shown in Figure 15. The effect of power-enrichment fuel trim strategy on $\mathrm{NO}_{x}$ emissions was statistically significant; however, there was also a marginally significant $(90 \%$ confidence level) interaction involving displacement. In particular, there was minimal change in average $\mathrm{NO}_{x}$ emissions for vehicles that applied LTFT at power enrichment; however, relative $\mathrm{NO}_{x}$ emissions tended to increase with engine displacement for vehicles that did not apply LTFT during power enrichment. Results for the $\mathrm{E} 10$ and $\mathrm{E} 15$ fuels were not as conclusive.

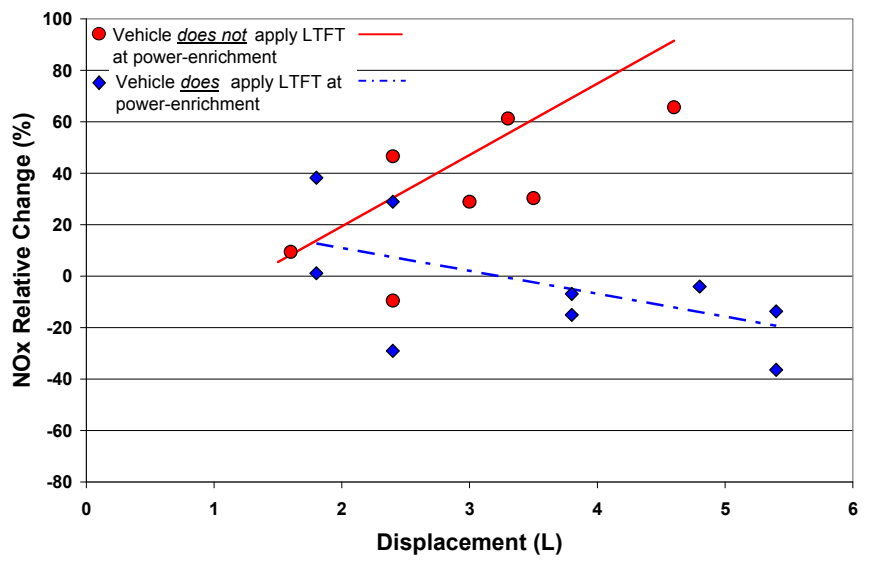

Figure 15: Change in relative composite $\mathrm{NO}_{X}$ composite emissions with $20 \%$ fuel ethanol by LTFT strategy and engine displacement. Interaction of LTFT strategy and engine displacement is marginally significant at the $90 \%$ confidence level.

There was no statistical evidence that engine characteristics influence how fuel ethanol content affects emissions of ethanol and aldehydes.

PHASE EMISSIONS ANALYSIS - Individual phase emissions were also considered both for the 16-vehicle fleet in aggregate and for the vehicle subgroup split as used above-those that applied LTFT at power enrichment and those that did not. As noted above, the LA92 was conducted as a three-phase test incorporating a 10-minute engine-off hot-soak period following phase 2. Phase 3 was then run as a hot-start replicate of the cold-start phase 1. Figures below focus on the 
aggregate vehicle results to maximize statistical significance due to the larger sample size.

Phase 1 emissions for the 16-vehicle fleet are shown in Figure 16 using the same graphing methodology as described for Figure 6. Comparing Figures 6 and 16, generally consistent fuel-effect trends in NMOG, NMHC, and $\mathrm{CO}$ are observed between composite and phase 1 results. NMOG emissions showed no statistically significant trend with fuel ethanol content; NMHC showed a statistically significant reduction of between $10 \%$ and $15 \%$ for all fuels relative to E0. CO reductions were between $5 \%$ and $10 \%$, but they were statistically significant only for E10. When phase 1 data were split between power-enrichment fuel trim strategy (not shown), CO reductions of $15 \%$ to $20 \%$ were observed for vehicles found to not apply LTFT during power enrichment. Almost no phase $1 \mathrm{CO}$ change was observed for the vehicle subgroup found to apply LTFT during power enrichment. Phase 2 results were similar, but with reduced statistical significance.

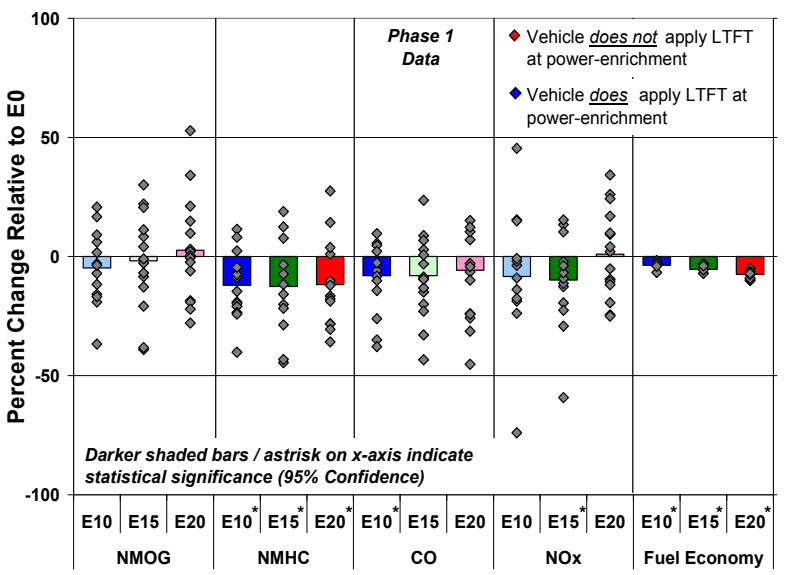

Figure 16: Percent change in phase 1 emissions and fuel economy relative to E0

Phase 3 emissions trends, shown in Figure 17, were similar to composite results for NMOG, NMHC, and CO, though with notable differences in statistical significance. NMOG and NMHC both showed statistically significant reductions of $15 \%$ to $35 \%$ for $E 10$ and E20, respectively, relative to E0; however, no significant trend for E15 was observed. CO showed statistically significant reductions of $40 \%$ to $50 \%$ relative to EO for all ethanol concentrations. Phase 3 mass emissions for NMOG, $\mathrm{NMHC}$, and $\mathrm{CO}$ were on average about one-fifth to onetenth of the values observed for phase 1. In general, NMOG, NMHC, and CO exhibited individual phase emissions trends consistent with composite results; mass emissions rates were driven primarily by phase 1 .

In contrast, phase $1 \mathrm{NO}_{\mathrm{x}}$ emissions trends shown in Figure 16 were not consistent with the composite results of Figure 6. Phase $1 \mathrm{NO}_{x}$ emission showed reductions for E10 and E15 of nearly 10\%, and the E15 result was statistically significant. Phase $2 \mathrm{NO}_{\mathrm{x}}$ emissions were generally consistent with composite results, showing no statistically significant trends. Phase $3 \mathrm{NO}_{x}$ emissions, however, showed statistically significant increases for all ethanol fuel concentrations. Increases were between $65 \%$ and $100 \%$ relative to E0. Vehicles found to not apply LTFT to power-enrichment operation (not shown) exhibited the highest $\mathrm{NO}_{x}$ emissions increases; results for E20 showed a statistically significant $160 \%$ increase relative to $\mathrm{E} 0$. Phase 3 mass emissions rates for $\mathrm{NO}_{x}$ were about $0.2 \mathrm{~g} / \mathrm{mile}$ on average - about one-third of phase 1 mass emissions rates and about twice the composite emissions values. In general, mass emissions rates for $\mathrm{NO}_{\mathrm{x}}$ were still driven by phase 1 values; however, the fuel-effect - especially for vehicles found to not apply LTFT to power-enrichment-was primarily driven by phase 3 results.

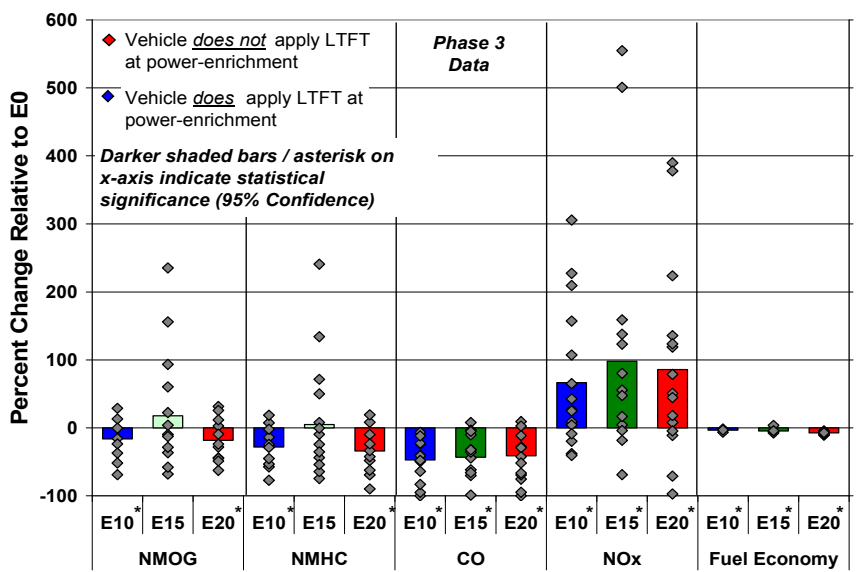

Figure 17: Percent change in phase 3 emissions and fuel economy relative to E0

Ethanol and aldehyde composite emissions trends were primarily driven by phase 1 results, both for mass emissions rates and fuel-effect results.

CATALYST TEMPERATURE EFFECTS - As expected, vehicles that did not apply LTFT to power-enrichment conditions were found to exhibit higher catalyst temperatures during WOT operation as fuel-ethanol content increased. These higher catalyst temperatures were expected because of leaner operation during WOT for this vehicle subgroup. Vehicles that were found to apply LTFT during WOT operation showed no significant change in peak catalyst temperature with ethanol content.

Figure 18 shows the average difference in peak catalyst temperature for $10 \%, 15 \%$, and $20 \%$ ethanol content relative to E0 for the 16 -vehicle fleet. For the 7 vehicles found to run leaner during power enrichment, a roughly linear increase in peak catalyst temperature was observed with increasing ethanol content. For E20, peak catalyst temperatures were seen to increase on average about $30^{\circ} \mathrm{C}$ relative to those for E0. For the 9 vehicles found to apply LTFT to power-enrichment operation, average peak catalyst temperatures were found to be 
unaffected by ethanol content, but with considerable scatter in the data. Catalyst temperatures during closedloop stoichiometric operation were seen to be generally lower with increasing ethanol content as a result of the cooling effect of ethanol on the combustion process (data not shown).

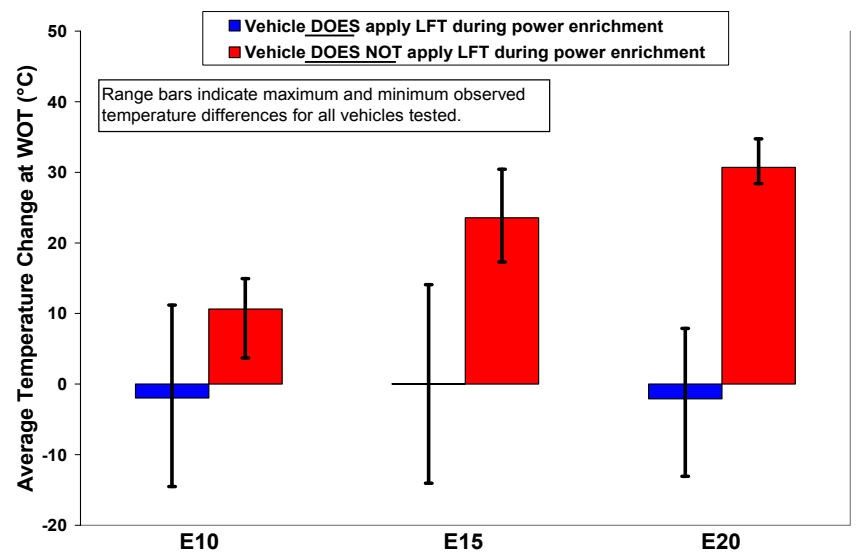

Figure 18: Change in catalyst temperature versus fuel type for wide-open throttle (WOT) power-enrichment conditions.

Catalyst temperature is important because catalyst durability is adversely affected by exposure to higher than design temperatures. EPA uses the Arrhenius relationship to predict catalyst life for emission control system durability compliance. ${ }^{21}$ According to this relationship, temperature has an exponential effect on predicted catalyst life. Because the effect of ethanol in the current study was either to increase catalyst temperature during power-enrichment operation (for one vehicle subgroup), or to decrease catalyst temperature during normal, closed-loop operation (for all vehicles tested), the overall effect of ethanol on a catalyst's full useful life was not clear. A full-useful-life durability study is needed to accurately determine such an effect.

\section{CONCLUSION}

This study quantified the short-term effects of mid-level ethanol blends (E0, E10, E15, and E20) on late-model, light-duty vehicle emissions and catalyst temperatures. The LA92 driving cycle was used for all emissions evaluations. Key conclusions are as follows:

1. For the aggregate vehicle set, increasing the ethanol content from $0 \%$ to $20 \%$ resulted in no significant effect on composite NMOG and $\mathrm{NO}_{x}$ emissions. $\mathrm{NMHC}$ and $\mathrm{CO}$ emissions were both reduced while ethanol and acetaldehyde emissions were both increased at all ethanol concentrations. Formaldehyde emissions increased at $10 \%$ ethanol but showed no further increase with increasing ethanol content.

2. Ethanol effects on tailpipe emissions can be differentiated according to ECU power-enrichment fueling strategy; vehicles that applied LTFT to power-enrichment operation and vehicles that did not apply LTFT to power-enrichment operation.

3. Vehicles that applied LTFT to power-enrichment operation showed no significant effect of ethanol content on LA92 composite emissions for NMOG, $\mathrm{NMHC}, \mathrm{CO}$, or $\mathrm{NO}_{x}$. Composite emissions of ethanol, acetaldehyde and formaldehyde, however, increased with increasing ethanol content.

4. Vehicles that did not apply LTFT to powerenrichment operation showed reductions in NMHC and $\mathrm{CO}$ and increases in $\mathrm{NO}_{\mathrm{x}}$, ethanol, and acetaldehyde with increasing ethanol content. Formaldehyde emissions were mostly unchanged.

5. NMOG and NMHC emissions showed a coupled effect with power-enrichment fuel trim strategy and vehicle power-to-weight ratio. As power-to-weight ratio increased, NMOG and NMHC emissions increased with increasing ethanol for vehicles that applied LTFT to power enrichment, while these emissions decreased for vehicles that did not apply LTFT to power enrichment.

6. $\mathrm{NO}_{x}$ emissions showed a coupled effect with powerenrichment fuel trim strategy and vehicle engine displacement. As engine displacement increased, $\mathrm{NO}_{x}$ emissions decreased with increasing ethanol for vehicles that applied LTFT to power enrichment, while $\mathrm{NO}_{x}$ emissions increased for vehicles that did not apply LTFT to power enrichment.

7. Composite emissions trends for NMOG, NMHC, and $\mathrm{CO}$ were generally consistent with phase emissions results for all three phases.

8. Composite emissions trends for ethanol, acetaldehyde, and formaldehyde were generally driven by phase 1 results.

9. Composite emissions trends for $\mathrm{NO}_{x}$ were strongly driven by phase 3 results.

10. Catalyst temperatures during WOT operation were higher for vehicles that did not apply LTFT during power-enrichment operation. Vehicles found to apply LTFT during power enrichment showed no significant difference in catalyst temperature during WOT operation.

\section{ACKNOWLEDGMENTS}

This work was sponsored by the U.S. Department of Energy (DOE) Office of Energy Efficiency and Renewable Energy (EERE) Biomass Program and the EERE Vehicle Technologies Program. The authors gratefully acknowledge the support of Program Managers Joan Glickman and Kevin Stork at DOE. Contributions from staff at each of the testing labsCDPHE, TRC, and ORNL - are also greatly appreciated. The authors also acknowledge the contributions of Argonne National Laboratory for contracting assistance at TRC. This work has benefited greatly from consultation with many technical experts in industry and other government agencies. 


\section{REFERENCES}

1. Energy Independence and Security Act of 2007, H.R. $6,110^{\text {th }}$ Congress, 2007-2008.

2. R. Bechtold, J. F. Thomas, S. P. Huff, J. P. Szybist, T. J. Theiss, B. H. West, M. Goodman, T. A. Timbario, "Technical Issues Associated with the Use of Intermediate Ethanol Blends (>E10) in the U.S. Legacy Fleet," ORNL/ TM-2007/37, August 2007.

3. D. Guerrieri, P. Caffrey, V. Rao, "Investigation into the Vehicle Exhaust Emissions of High Percentage Ethanol Blends," SAE Technical Paper 950777, 1995.

4. Orbital Engine Company, "Market Barriers to the Uptake of Biofuels Study, A Testing Based Assessment to Determine Impacts of a $20 \%$ Ethanol Gasoline Fuel Blend on the Australian Passenger Vehicle Fleet," Report to Environment Australia, March 2003.

5. A. M. Hochhauser, "Review of Prior Studies of Fuel Effects on Vehicle Emissions," CRC Report No. E-84, Coordinating Research Council, Alpharetta, GA, 2008.

6. California Environmental Protection Agency, Air Resource Board, "California Non-Methane Organic Gas Test Procedure," July 2002.

7. K. Knoll, B. West, W. Clark, R. Graves, J. Orban, S. Przesmitzki, T. Theiss, "Effects of Intermediate Ethanol Blends on Legacy Vehicles and Small Non-Road Engines, Report 1 - Updated," NREL/TP-540-43543 and ORNL/TM-2008/117, February 2009.

8. W. O. Siegl, J. F. O. Richert, T. E. Jensen, D. Schuetzle, S. J. Swarin, J. F. Loo, A. Prostak, D. Nagy, A. M. Schlenker, "Improved Emissions Speciation Methodology for Phase II of the Auto/Oil Air Quality Improvement Research Program-Hydrocarbons and Oxygenates," SAE Technical Paper 930142, 1993.

9. J. F. Loo and D. T. Parker, "Evaluation of a Photoacoustic Gas Analyzer for Ethanol Vehicle Emissions Measurement," SAE Technical Paper 2000-01-0794, 2000 .

10. "Energy Policy Act (EPAct)/Testing Status," Presentation by EPA to CRC Emissions Committee Meeting, RFS2 Docket, EPA-HQ-OAR-2005-0161, Item EPA-HQ-OAR0161-0643, May 22, 2008.

11. "Mid-Level Ethanol Blends Catalyst Durability Study Screening," CRC Report No. E-87-1, Coordinating Research Council, Alpharetta, GA, 2009.

12. California Environmental Protection Agency, Air Resources Board, "Driving Patterns and Emissions: A New Testing Cycle," Research Notes No. 96-11, 1996.

13. T. D. Durbin et al., "The Effect of Fuel Sulfur on $\mathrm{NH}_{3}$ and Other Emissions from 2000-2001 Model Year Vehicles," CRC Report No. E-60, Coordinating Research Council, Alpharetta, GA, 2003.
14. M. Skoglundh and E. Fridell, "Strategies for Enhancing Low-Temperature Activity," Topics in Catalysis, Vol. 28, 79-87, 2004.

15. T. Kobayashi, S. Nagatomo, K. Ishikawa, T. Yamada, "Improvement of $\mathrm{NO}_{x}$ Performance and Thermal Stability in Pd-Based Catalyst," SAE Technical Paper 2000-012927, 2000.

16. J. Li, J. Theis, W. Chun, C. Goralski, R. Kudla, J. Ura, W. Watkins, M. Chattha, R. Hurley, "Sulfur Poisoning and Desulfation of the Lean NOx Trap," SAE Technical Paper 2001-01-2503, 2001.

17. J. E. Thoss and J. Rieck, "The Impact of Fuel Sulfur Level on FTP Emissions - Effect of PGM Catalyst Type," SAE Technical Paper 970737, 1997.

18. C. H. Schleyer, R. F. Gunst, J. Eckstrom, J. Freel, R. A. Gorse, G. J. Barnes, K. D. Eng, M. Natarajan, A. M. Schlenker, "Effect of Fuel Sulfur on Emissions in California Low Emission Vehicles," SAE Technical Paper 982726, 1998.

19. C. H. Schleyer, K. D. Eng, R. A. Gorse, R. F. Gunst, J. Eckstrom, J. Freel, M. Natarajan, A. M. Schlenker, "Reversibility of Sulfur Effects on Emissions of California Low Emission Vehicles," SAE Technical Paper 1999-011544, 1999.

20. J. Yanowitz and R. L. McCormick, "Effect of E85 on Tailpipe Emissions from Light-Duty Vehicles," Journal of Air \& Waste Management, Vol. 59, 172-182, 2009.

21. Code of Federal Regulations: Protection of the Environment, Title 40 CFR 86.1823-08.

22. E. Nam, "Drive Cycle Development and Real-World Data in the United States," Presentation at the United Nations Economic Commission for Europe, WLTP-02-17, January 2009.

23. H. C. Watson, E. E. Milkins, M. O. Preston, C Chittleborough, B. Alimoradian, "Predicting Fuel Consumption and Emissions - Transferring Chassis Dynamometer Results to Real Driving Conditions," SAE Technical Paper 830435, 1983.

24. H. C. Watson, "Effects of a Wide Range of Drive Cycles on the Emissions from Vehicles of Three Levels of Technology," SAE Technical Paper 950221, 1995.

\section{DISCLAIMER}

This manuscript has been authored by a contractor of the U.S. government under contract numbers NREL/DEAC36-08-GO28308 and ORNL/DE-AC05-00OR22725. Accordingly, the U.S. government retains a nonexclusive, royalty-free license to publish or reproduce the published form of this contribution, or allow others to do so for the U.S. government. 


\section{DEFINITIONS, ACRONYMS, ABBREVIATIONS}

$\begin{array}{ll}\text { ANL } & \begin{array}{l}\text { Argonne National Laboratory } \\ \text { ASTM }\end{array} \\ \text { American Society for Testing and } \\ \text { Materials } \\ \text { CFPHE } & \begin{array}{l}\text { Colorado Department of Public } \\ \text { Health and Environment }\end{array} \\ \text { CO } & \begin{array}{l}\text { Code of Federal Regulations } \\ \text { carbon monoxide }\end{array} \\ \text { CRC } & \text { Coordinating Research Council } \\ \text { DOE } & \text { U.S. Department of Energy } \\ \text { DNPH } & \text { dinitrophenylhydrazine } \\ \text { DVPE } & \text { dry vapor pressure equivalent } \\ \text { ECU } & \text { engine control unit } \\ \text { EERE } & \text { Office of Energy Efficiency and } \\ & \text { Renewable Energy } \\ \text { EISA } & \text { Energy Independence and Security } \\ & \text { Act } \\ \text { EGO } & \text { exhaust gas oxygen (sensor) } \\ \text { EPA } & \text { Environmental Protection Agency } \\ \text { EPAct } & \text { Energy Policy Act } \\ \text { FFV } & \text { flexible-fuel vehicle } \\ \text { FID } & \text { flame ionization detector } \\ \text { FTP } & \text { Federal Test Procedure } \\ \text { GM } & \text { General Motors } \\ \text { LEV } & \text { low-emission vehicle }\end{array}$

LHV

LTFT

MIL

NLEV

NMHC

NMOG

$\mathrm{NO}_{X}$

NREL

OBD

OEM

ORNL

RFS

SG

SRC

STFT

$\mathrm{THC}$

TRC

UEGO

ULEV

VW

WOT lower heating value long-term fuel trim malfunction indicator light National Low Emissions Vehicle nonmethane hydrocarbons nonmethane organic gas oxides of nitrogen National Renewable Energy Laboratory on-board diagnostics original equipment manufacturer Oak Ridge National Laboratory Renewable Fuel Standard specific gravity standard road cycle short-term fuel trim total hydrocarbon Transportation Research Center universal exhaust gas oxygen ultra-low emission vehicle Volkswagen wide-open throttle 